\title{
Teaching-Learning Based Optimization of Nonlinear Isolation Systems under Far-Fault Earthquakes
}

\author{
Seda ÖNCÜ-DAVAS ${ }^{1}$ \\ Rasim TEMÜR ${ }^{2}$ \\ Cenk ALHAN ${ }^{3}$
}

\begin{abstract}
Seismic isolation systems exposed to far-fault earthquakes can reduce floor accelerations and story drift ratios to acceptable levels. However, they exhibit different structural performances in each earthquake due to different excitation frequency contents. By optimizing the isolation system parameters, their performance may be maintained at the best level under different farfault earthquakes. In this study, the optimization of the parameters of the nonlinear isolation system of a 5-story benchmark building is performed by Teaching-Learning Based Optimization (TLBO) algorithm to minimize peak floor accelerations under historical farfault earthquakes with and without exceeding a specified base displacement limit. According to the results of the analyses, it can be said that TLBO algorithm is a robust algorithm with low standard deviations for determining optimum nonlinear isolation system parameters.
\end{abstract}

Keywords: Seismic isolation, nonlinear isolation system, optimization, far-fault earthquake.

\section{INTRODUCTION}

Seismic isolation is one of the structural control techniques used to protect buildings against severe earthquake effects and improve their structural performance. The main principle of seismic isolation is based on lengthening the fundamental period of the structure via the use of laterally flexible isolation elements placed between the foundation and the structure. As the structure period is moved away from the dominant earthquake period, effective earthquake forces acting on the structure are reduced. In addition, earthquake energy can be dissipated due to the hysteretic damping during the earthquake; thus, the energy transmitted from the foundation to the structure can be limited. Also, the superstructure moves like a

Note:

- This paper was received on October 16, 2019 and accepted for publication by the Editorial Board on June 26, 2020.

- Discussions on this paper will be accepted by March 31, 2022.

- https://doi.org/10.18400/tekderg.633636

1 İstanbul University - Cerrahpaşa, Department of Civil Engineering, İstanbul, Turkey seda.oncu@istanbul.edu.tr - https://orcid.org/0000-0001-5023-1980

2 İstanbul University - Cerrahpaşa, Department of Civil Engineering, İstanbul, Turkey temur@istanbul.edu.tr - https://orcid.org/0000-0001-7154-2286

3 İstanbul University - Cerrahpaşa, Department of Civil Engineering, İstanbul, Turkey cenkalhan@istanbul.edu.tr -https://orcid.org/0000-0002-6649-8409 
rigid block on the isolation system, which helps to reduce the inter-story drifts further. This way, inter-story drifts and floor accelerations can be reduced simultaneously [1]. Thus, structural and/or non-structural damages that may occur in the superstructure can be avoided.

Seismic isolation technique is used for both improving seismic performance of existing structures and earthquake-resistant design of new structures. This method is mostly preferred in hospitals, financial centers, telecommunication centers, etc. where serviceability is essential during and after earthquakes. Seismic isolation has attracted significant attention from researchers during the last forty years and is practically applied especially in the US, Japan, China, New Zealand, Italy, and Turkey [2]. The isolators used in the seismic isolation systems can be categorized into two main groups as rubber-based and friction-based. Rubberbased seismic isolators are also divided into three main types as low damping rubber bearings (LDRB), high damping rubber bearings (HDRB), and lead-rubber bearings (LRB). Among them, high damping rubber bearings (HDRB) and lead-core rubber bearings (LRB) exhibit nonlinear hysteretic behavior. The behavior is typically close to bi-linear, which is clearly observed in the force-displacement relationships of such isolators [3].

Properly designed seismic isolation systems can be very successful by effectively reducing floor accelerations and inter-story drift ratios to acceptable levels without causing excessive base displacement demands when they are especially subjected to typical far-fault earthquakes. The observed performances of seismically isolated buildings under historical earthquakes support this finding. For example, the peak top floor acceleration of the seismically isolated USC hospital building under the 1994 Northridge earthquake was reduced to $50 \%$ of the maximum ground acceleration. Peak inter-story drifts were also found to be less than $30 \%$ of the value specified in the design code [4]. Likewise, seismically isolated West Japan Computer Center Building performed well in the 1995 Kobe earthquake [1]. On the other hand, seismically isolated buildings can be exposed to far-fault earthquakes with different frequency contents which would lead to different base displacement and floor acceleration demands. In this case, by optimizing the isolation system parameters, it can be ensured that optimum seismic performance is attained under different far-fault earthquakes.

Optimum isolation system parameters can be obtained by using metaheuristic optimization algorithms that provide successful results in many engineering problems. Metaheuristic optimization algorithms employ processes in which one or more objective functions that are determined explicitly specific to the problem and are maximized or minimized within the allowed number of cycles. Examples of metaheuristic algorithms, most of which are inspired by nature, are given as Genetic Algorithm (GA) [5], Ant Colony Optimization (ACO) [6], Particle Swarm Optimization (PSO) [7], Artificial Bee Colony Optimization (ABC) [8] and Teaching-Learning Based Optimization (TLBO) [9].

Optimum isolation system parameters can also be determined by systematically changing these parameters and monitoring the seismic performance. In such studies [10-12], isolation system parameters that yield the best seismic performance are selected and labeled as the optimum. However, true optimization can only be reached by using optimization methods. There exist a very limited number of studies in the literature in which the optimum values of the isolation system parameters are determined using optimization methods. In a study conducted in this context [13], the parameters of the linear isolation system of seismically isolated buildings exposed to historical earthquakes were optimized by the Harmony Search (HS) method. In the study conducted by Çerçevik and Avşar [14], Crow Search algorithm 
was used to determine the optimum linear isolation system parameters of the same benchmark seismically isolated building. For optimizing nonlinear isolation systems, the Genetic Algorithm (GA), which is another old optimization algorithm, was applied by Pourzeynali and Zarif [15] to high rise shear-type seismically isolated building under strong ground motions. Unlike these studies, in this study, optimization of nonlinear isolation system parameters via Teaching-Learning Based Optimization (TLBO) algorithm is presented in the context of a medium-rise prototype building exposed to historical far-fault earthquakes. The optimization process has been realized using TLBO because this algorithm typically gives more consistent results compared to many other meta-heuristic algorithms. Furthermore, unlike many other meta-heuristic algorithms, TLBO does not require any algorithm-specific parameters [16-19]. The objective function in determining the optimum values of the isolation system parameters in this study is set as minimizing peak top floor acceleration with and without exceeding a specified base displacement limit. Thus, the robustness of TLBO is evaluated for obtaining optimum values of the non-linear isolation system parameters.

In this context, primarily the formulation of nonlinear seismic isolation system is introduced in Section 2. The properties of the TLBO algorithm used in the study are briefly given in the next section. Then, the implementation of TLBO algorithm to the optimization of nonlinear isolation systems is described in Section 4. Finally, optimization process is performed for a numerical example and the results are presented.

\section{STRUCTURAL MODEL}

The structural model of the seismically isolated building used in this study consists of a superstructure and a non-linear base isolation system containing rubber bearings with nonlinear behavior (Figure 1 (b)) [10]. A stick model with floor stiffnesses $\mathrm{k}_{1}=\mathrm{k}_{2}=\mathrm{k}_{3}=\mathrm{k}_{4}=\mathrm{k}_{5}$ and floor masses $\mathrm{m}_{1}=\mathrm{m}_{2}=\mathrm{m}_{3}=\mathrm{m}_{4}=\mathrm{m}_{5}=\mathrm{m}_{\mathrm{izo}}$ is used for which the superstructure floor stiffness and floor mass values are adjusted so that the first-mode fixed-base fundamental period of the superstructure is $0.5 \mathrm{~s}$. The modal damping ratio of the superstructure is taken as $3 \%$ for all modes. Besides, it is assumed that the displacements in the superstructure stay within elastic limits during the earthquake simulations.

The nonlinear behavior of isolation systems can be defined mathematically by the Bouc-Wen model [20] shown in Figure 1 (a). The main mechanical parameters of the rubber isolators are the pre-yield stiffness $\left(K_{1}\right)$, the post-yield stiffness $\left(K_{2}\right)$, the characteristic force $(Q)$, the yield force $\left(F_{y}\right)$ and the yield displacement $\left(D_{y}\right)$. Here, the maximum strength $\left(F_{\max }\right)$ corresponds to maximum base displacement $(D)$. The total post-yield stiffness $\left(K_{2 t}\right)$ can be calculated using Equation 1, depending on the target isolation system period $\left(T_{0}\right)$ and the total mass of the building $\left(m_{t}\right)[10]$.

$$
T_{0}=2 \pi\left(m_{t} / K_{2 t}\right)^{1 / 2}
$$

In determining the total characteristic force $\left(Q_{t}\right)$ of the isolation system, the target total characteristic force ratio $\left(Q_{t} / W\right)$ is taken into account. By considering the total characteristic force $\left(Q_{t}\right)$ and the yield displacement $\left(D_{y}\right)$, the total pre-yield stiffness is calculated as [1]: 


$$
K_{1 t}=Q_{t} / D_{y}+K_{2 t}
$$

The post-yield to pre-yield stiffness ratio is obtained by Equation (3).

$$
\alpha=K_{2 t} / K_{1 t}
$$

Depending on the total pre-yield stiffness $\left(K_{1 t}\right)$ and the yield displacement $\left(D_{y}\right)$, the total yield force $\left(F_{y t}\right)$ is calculated as in Equation (4)

$$
F_{y t}=D_{y} K_{1 t}
$$

Then, by dividing $K_{1 t}, K_{2 t}, Q_{t} / W$, and $F_{y t}$ by the total number of isolators, the pre-yield stiffness $K_{1}$, the post-yield stiffness $K_{2}$, the characteristic force $(Q)$ and the yield strength $F_{y}$ are obtained for each individual rubber bearing.

(a)

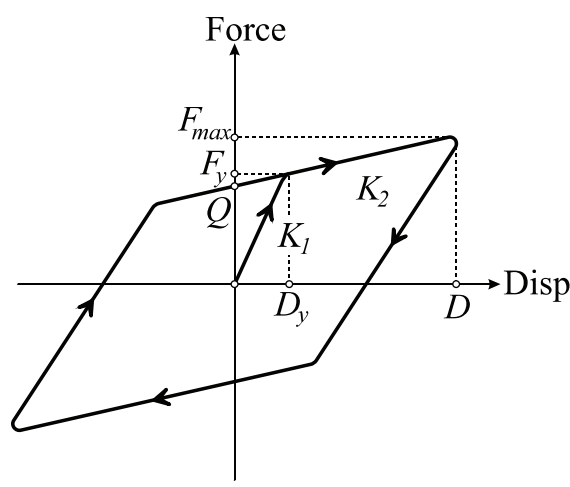

(b)

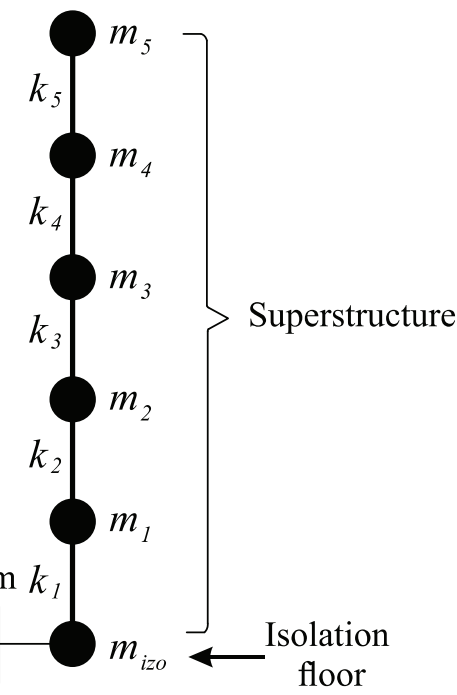

Figure 1 - (a) Bi-linear hysteretic model that represents nonlinear isolation system behavior, (b) Schematic representation of the structural model

\section{TEACHING-LEARNING BASED OPTIMIZATION (TLBO) ALGORITHM}

Optimization algorithms are processed in a way where one or more objective functions determined in a problem-specific manner are maximized and/or minimized within the allowed number of cycles. One of the metaheuristic algorithms is "Teaching-Learning Based Optimization" (TLBO) algorithm presented by Rao et al. [9] who were inspired by the learning process. According to TLBO, the learning process is divided into 'teacher phase' and 'learner phase'. The first stage represents the learners' learning process from the teacher. 
At this stage, a teacher attempts to increase the average success of the class in the subject taught by her/him and new solutions are generated using Equation (5)

$$
X_{\text {new }}=X_{\text {old }}+r n d \cdot\left(X_{\text {teacher }}-T_{F} \cdot X_{\text {mean }}\right)
$$

where $X_{\text {new }}$ is a new value, $X_{\text {old }}$ is the former value, rnd is the random number generated between 0 and 1, $X_{\text {teacher }}$ is the value of the best solution, $T_{F}$ is the teaching factor, and $X_{\text {mean }}$ is the mean value of all candidate solutions. Teaching factor takes a value of either 1 or 2 and is formulated as:

$$
T_{F}=\operatorname{round}[1+r n d]
$$

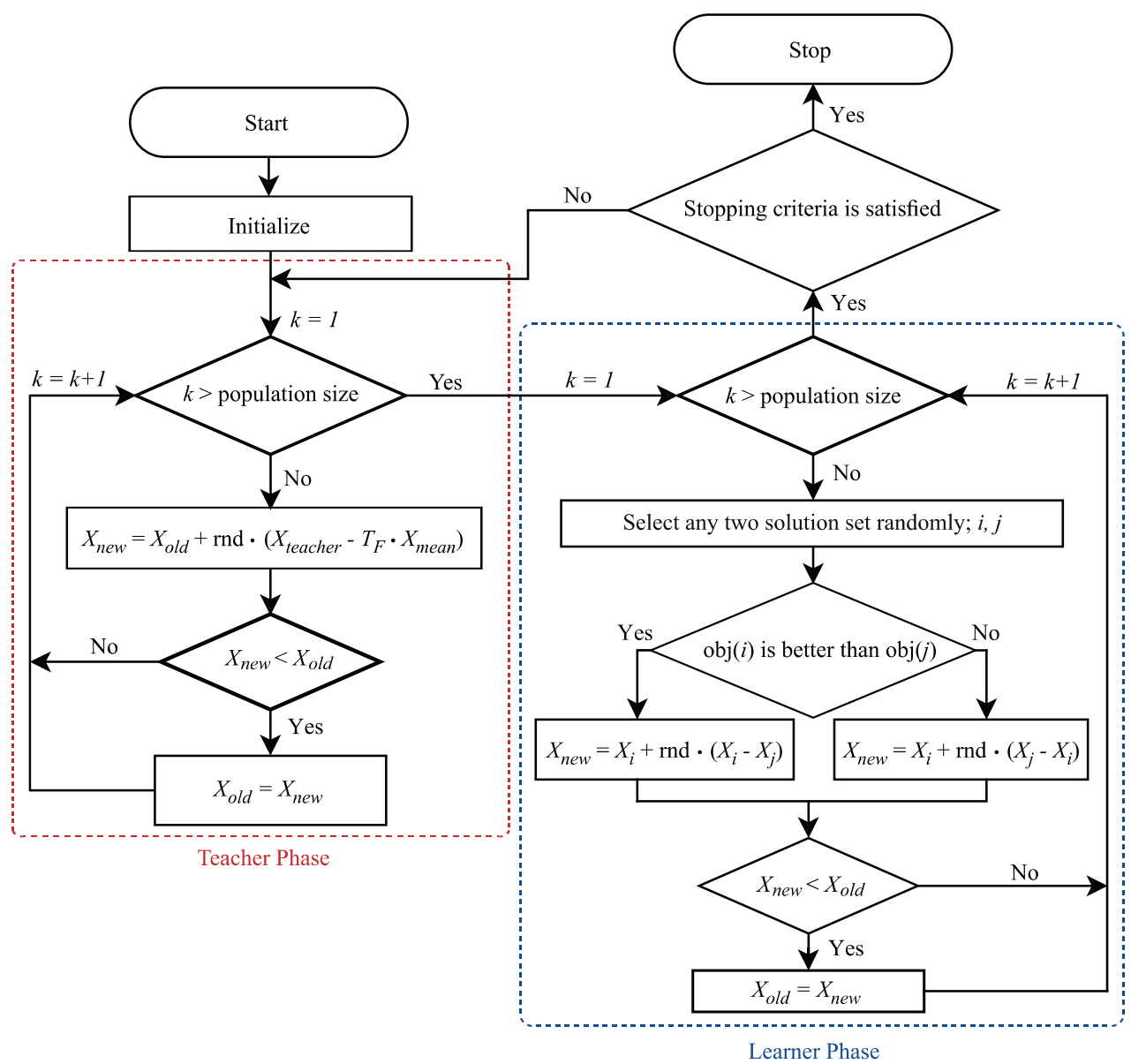

Figure 2 - The flowchart of the TLBO algorithm 
The second stage represents the learners' learning experience through out-of-class and group work. In other words, a learner develops his/her knowledge by randomly interacting with other learners. The population determined within the algorithm consists of learners and teachers. New solutions are generated as below at the learner phase:

$$
X_{\text {new }}=\left\{\begin{array}{lll}
X_{\text {old }}+r n d \cdot\left(X_{i}-X_{j}\right) & \text { if } & f\left(X_{i}\right)>f\left(X_{j}\right) \\
X_{\text {old }}+r n d \cdot\left(X_{j}-X_{i}\right) & \text { if } & f\left(X_{j}\right)>f\left(X_{i}\right)
\end{array}\right.
$$

where $X_{i}$ and $X_{j}$ are randomly selected solutions that are different from each other. If the new solutions are better than the previous related solutions, they are replaced with each other. The flowchart for the teaching-learning based optimization (TLBO) algorithm is depicted in Figure 2 .

\section{IMPLEMENTATION OF TLBO FOR THE NON-LINEAR ISOLATION SYSTEM OPTIMIZATION}

The scope of the optimization problem examined in this study is to determine the optimum value of the non-linear seismic isolation system parameters of a seismically isolated building via the use of TLBO algorithm. For this scope, three independent design variables $\left(X_{1}, X_{2}\right.$, $X_{3}$ ) are used to describe the mechanical parameters of the non-linear isolation system, as given in Section 2. Among these mechanical parameters, the isolation system period $\left(X_{1}=T_{0}\right)$, the yield displacement $\left(X_{2}=Q_{t} / W\right)$, and the total characteristic force ratio $\left(X_{3}=D_{y}\right)$ are optimized by selecting them as design variables. Once the design variables are optimized, the dependent variables $K_{1 t}, K_{2 t}, F_{y t}$, and $\alpha$ are obtained via Equations (1)-(4).

\subsection{Constraints}

During the solution of the optimization problem, there may also be parameters set as constraints. A set of constraints to which the solution is subjected to can generally be expressed as follows:

lower bound $\leq g_{j}(X) \leq$ upper bound $, \quad j=1, m$

in which $m$ is the number of constraints, where $m$ is equal to 2 in this study.

While optimizing the independent design variables, the post-yield to pre-yield stiffness ratio $(\alpha)$ is determined as a constraint $\left(\mathrm{g}_{1}(X)\right)$ to avoid values beyond reasonable limits representing rubber bearings. In this study, the upper and lower limits of $g_{1}(X)$ are determined as:

$0.025 \leq g_{1}(X) \leq 0.40$ 
The other constraint of the optimization problem $\left(g_{2}(X)\right)$ is considered as the peak base displacement limit ( $\left.D_{\text {limit }}\right)$. In this study, $g_{2}(X)$ is determined as $15 \mathrm{~cm}$, which may be considered as an economical design displacement value for far-fault regions.

$$
g_{2}(X) \leq 15 \mathrm{~cm}
$$

Further information on the constraints used the in optimization problem is given in the Numerical Example Section.

\subsection{Objective Function}

In this study, the objective function $f(X)$ is determined under the above-mentioned constraints $\left(g_{1}(X), g_{2}(X)\right)$ during the optimization of the nonlinear isolation system as follows:

$$
f(X)=\min (p t f a(X))+\sum \text { penalty }
$$

where $X$ is the design variable vector. The design variable vector comprises of total independent design variables. The information about the design variables of this study is given in the Numerical Example Section.

$$
X=\left\{X_{1}, X_{2}, X_{3}\right\}
$$

In the optimization process, if the specified constraints are violated, penalties having a considerable value are assigned to the objective function. Penalty values are calculated separately for the base displacement constraint and the post-yield to pre-yield stiffness ratio $(\alpha)$ constraint as follows:

$$
\text { penalty }(D)=\left\{\begin{array}{ccc}
\left(\left(p b d-D_{\text {limit }}\right) \cdot 1000+1\right)^{2}-1 & \text { if } & p b d>D_{\text {limit }} \\
0 & \text { if } & p b d \leq D_{\text {limit }}
\end{array}\right.
$$

Here, penalty $(D)$ is the displacement penalty function, $p b d$ is the peak base displacement, $D_{\text {limit }}$ is the base displacement limit.

$$
\text { penalty }(\alpha)=\left\{\begin{array}{ccc}
\left(\left(\alpha-\alpha_{\max }\right) \cdot 1000+1\right)^{2}-1 & \text { if } & \alpha>\alpha_{\max } \\
\left(\left(\alpha_{\min }-\alpha\right) \cdot 1000+1\right)^{2}-1 & \text { if } & \alpha<\alpha_{\min } \\
0 & \text { if } & \alpha_{\min }<\alpha<\alpha_{\max }
\end{array}\right.
$$

Where, penalty $(\alpha)$ is the penalty function for post-yield to pre-yield stiffness ratio, $\alpha_{\max }$ is the upper limit for $\alpha$ and $\alpha_{\min }$ is the lower limit for $\alpha$. At the end of the optimization process, the final result is reached when the penalty value is equal to 0 . In other words, reaching a penalty value of 0 means that the specified constraints are met. 


\section{NUMERICAL EXAMPLE}

In order to obtain the optimum values of non-linear seismic isolation system parameters of the 5-story benchmark seismically isolated building (Figure 1) exposed to historical far-fault earthquakes, the non-linear time-history analyses are performed in 3D-BASIS software [21]. As seen in Figure 3, the optimization process is carried out by recursively running 3D-BASIS software simultaneously with the optimization program generated in MATLAB in the context of this study that employs TLBO algorithm. In the TLBO algorithm, whose flowchart is shown in Figure 2, parameters are determined with design constants and lower and upper limits of design variables. Design constants consist of the mathematical model of the superstructure and the number of isolators, while the design variables consist of the main mechanical parameters of the seismic isolation system.

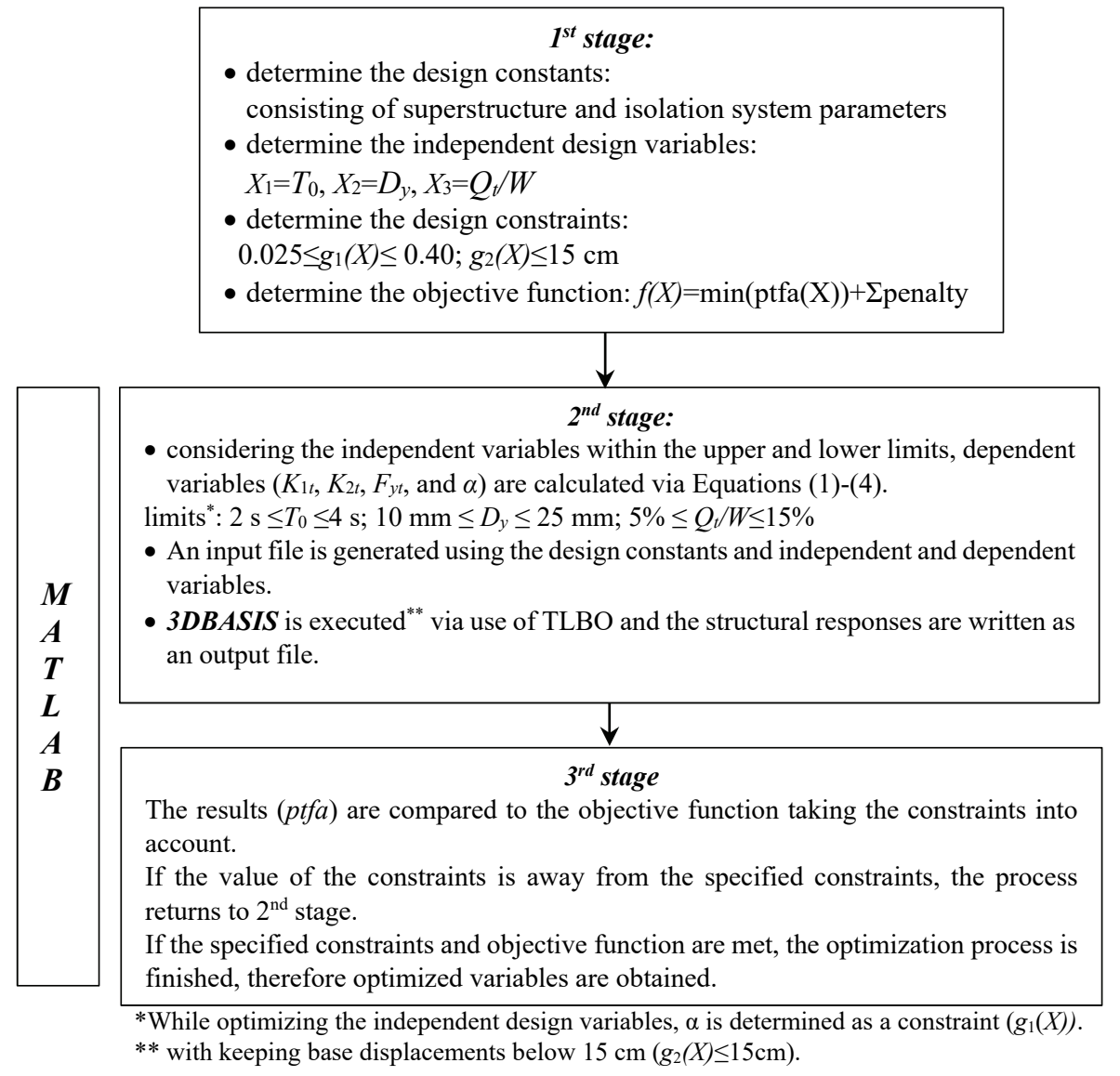

Figure 3 - Schematic illustration of optimization process via use of 3DBASIS and MATLAB software

A range of values is to be specified for each design variable that indicate the upper and lower limit values for the independent design variables. Among the design variables, the isolation 
system period $\left(X_{1}=T_{0}\right)$ is specified to remain in the range of $2 \mathrm{~s}$ to $4 \mathrm{~s}$, which is a typical range for practical applications [22]. Similarly, the yield displacement $\left(X_{2}=D_{y}\right)$ is selected to be optimized within the range of $10 \mathrm{~mm}$ to $25 \mathrm{~mm}$ which is a suitable range for rubber isolators ([10], [23]), while the characteristic force ratio $\left(X_{3}=Q_{t} / W\right)$ is taken in the range of $5 \%$ to $15 \%$ which are typically the smallest and largest values in practical applications ([24], [25]).

While optimizing the independent design variables, the post-yield to pre-yield stiffness ratio $(\alpha)$ is determined as a constraint since otherwise it may attain values beyond reasonable limits representing rubber bearings. According to a study presented by Dicleli and Buddaram [24], the post-yield stiffness to pre-yield stiffness ratio values of 0.025 to 0.10 are attributed to lead-rubber bearings, and the values of 0.133 to 0.40 are attributed to high-damping rubber bearings. Thus, the assumed range of post-yield stiffness to pre-yield stiffness ratio values in this study encompasses a range that represents rubber-based isolators (i.e. both lead-rubber and high-damping rubber bearings). In this study, $\alpha$ is bound by a lower limit of 0.025 and an upper limit of $0.40\left(0.025 \leq g_{1}(X) \leq 0.40\right)$.

Since the goal of seismic isolation is set as reducing floor accelerations while keeping base displacements below practical and economic limits, the other constraint of this optimization problem $\left(g_{2}(X)\right)$ is considered as the peak base displacement $(p b d)$. In the literature (e.g. [26]-[28]), it has been observed that the base displacements of the buildings with seismic isolation systems under far-fault earthquakes vary between 10 and $20 \mathrm{~cm}$. Thus, the peak base displacement constraint is determined as $15 \mathrm{~cm}$ for far-fault earthquakes which may be considered as an economical design displacement value for far-fault regions. It should be noted that this limit may vary on a project basis. In this study, the optimization process is carried out by minimizing the peak top floor accelerations (ptfa) while keeping base displacements below $15 \mathrm{~cm}\left(g_{2}(X) \leq 15 \mathrm{~cm}\right)$. The optimization is also carried out without considering the peak base displacement constraint (only for $0.025 \leq g_{1}(X) \leq 0.40$ ).

\subsection{Earthquake Records}

Five different far-fault earthquakes given in Table 1 are used in the optimization process. They are suggested by FEMA P695 [29] and retrieved from the PEER database [30]. In Table 1 , information such as recording station, ground motion component name, and peak ground acceleration (PGA), peak ground velocity (PGV), earthquake magnitude $\left(\mathrm{M}_{\mathrm{w}}\right)$, and closest distances to the fault (r) values are presented. In the time-history analyses, the determined components are applied uni-directionally.

Table 1 - Properties of historical earthquake records

\begin{tabular}{llllllll}
\hline Earthquake & Date & Station & Component & $\begin{array}{l}\text { PGA } \\
(\mathbf{g})\end{array}$ & $\begin{array}{l}\text { PGV } \\
(\mathbf{m} / \mathbf{s})\end{array}$ & $\mathbf{M}_{\boldsymbol{w}}$ & $\begin{array}{c}\mathbf{r} \\
(\mathbf{k m})\end{array}$ \\
\hline Imperial Valley-06 & $10 / 15 / 1979$ & Delta & H-DLT262 & 0.35 & 0.33 & 6.53 & 22 \\
Kocaeli & $8 / 17 / 1999$ & Düzce & DZC270 & 0.36 & 0.56 & 7.51 & 15.4 \\
Landers & $6 / 28 / 1992$ & Coolwater & CLW-TR & 0.42 & 0.43 & 7.28 & 19.7 \\
Northridge & $1 / 17 / 1994$ & Canyon Country & LOS270 & 0.47 & 0.41 & 6.69 & 12.4 \\
Northridge-01 & $1 / 17 / 1994$ & Beverly Hills & MUL279 & 0.49 & 0.67 & 6.69 & 17.2 \\
\hline
\end{tabular}




\subsection{Optimum Population Size}

Unlike many other algorithms, TLBO does not need any algorithm-specific parameters. The population size, which is the common control parameter of all heuristic algorithms, is adequate for TLBO to run. Population size affects algorithm performance and the appropriate population size for the type of problem should be determined. Therefore, eight different population sizes are investigated as 5, 10, $1520,25,30,35$, and 40. Results of meta-heuristic optimization algorithms need to be statistically evaluated because they work with randomly generated numbers. For this reason, one hundred independent optimization processes are performed for each population size under five different far-fault earthquake records given in Table 1. The statistical results of the optimization processes, which include the maximum, the minimum, and the mean values and the standard deviations of the peak top floor acceleration ( $\mathrm{ptfa}$ ), are presented in Table 2.

Table 2 - The peak top floor acceleration $(\mathrm{ptfa})^{1}$ results obtained from 100 independent optimization process considering different population size without the peak base displacement constraint.

\begin{tabular}{|c|c|c|c|c|c|c|c|c|c|}
\hline \multirow{2}{*}{$\begin{array}{l}\text { Earthquake } \\
\text { Record }\end{array}$} & & \multicolumn{8}{|c|}{ Population Size } \\
\hline & & 5 & 10 & 15 & 20 & 25 & 30 & 35 & 40 \\
\hline \multirow{4}{*}{ CLW-LN } & Min. $\left(\mathrm{m} / \mathrm{s}^{2}\right)$ & 1.22 & 1.22 & 1.22 & 1.22 & 1.22 & 1.22 & 1.22 & 1.22 \\
\hline & $\operatorname{Max} .\left(\mathrm{m} / \mathrm{s}^{2}\right)$ & 2.06 & 1.22 & 1.22 & 1.22 & 1.22 & 1.22 & 1.22 & 1.22 \\
\hline & $\operatorname{Mean}\left(\mathrm{m} / \mathrm{s}^{2}\right)$ & 1.26 & 1.22 & 1.22 & 1.22 & 1.22 & 1.22 & 1.22 & 1.22 \\
\hline & St. Dev. & 0.17 & 0.00 & 0.00 & 0.00 & 0.00 & 0.00 & 0.00 & 0.00 \\
\hline \multirow{4}{*}{ DZC270 } & Min. $\left(\mathrm{m} / \mathrm{s}^{2}\right)$ & 1.44 & 1.44 & 1.44 & 1.44 & 1.44 & 1.44 & 1.44 & 1.44 \\
\hline & $\operatorname{Max} .\left(\mathrm{m} / \mathrm{s}^{2}\right)$ & 1.86 & 1.55 & 1.69 & 1.61 & 1.44 & 1.44 & 1.44 & 1.44 \\
\hline & $\operatorname{Mean}\left(\mathrm{m} / \mathrm{s}^{2}\right)$ & 1.51 & 1.44 & 1.45 & 1.45 & 1.44 & 1.44 & 1.44 & 1.44 \\
\hline & St. Dev. & 0.09 & 0.02 & 0.03 & 0.02 & 0.00 & 0.00 & 0.00 & 0.00 \\
\hline \multirow{4}{*}{ H-DLT362 } & Min. $\left(\mathrm{m} / \mathrm{s}^{2}\right)$ & 0.97 & 0.97 & 0.97 & 0.97 & 0.97 & 0.97 & 0.97 & 0.97 \\
\hline & $\operatorname{Max} .\left(\mathrm{m} / \mathrm{s}^{2}\right)$ & 1.50 & 0.97 & 0.97 & 0.97 & 0.97 & 0.97 & 0.97 & 0.97 \\
\hline & $\operatorname{Mean}\left(\mathrm{m} / \mathrm{s}^{2}\right)$ & 0.99 & 0.97 & 0.97 & 0.97 & 0.97 & 0.97 & 0.97 & 0.97 \\
\hline & St. Dev. & 0.09 & 0.00 & 0.00 & 0.00 & 0.00 & 0.00 & 0.00 & 0.00 \\
\hline \multirow{4}{*}{ LOS 270} & $\operatorname{Min} .\left(\mathrm{m} / \mathrm{s}^{2}\right)$ & 0.99 & 0.99 & 0.99 & 0.99 & 0.99 & 0.99 & 0.99 & 0.99 \\
\hline & $\operatorname{Max} .\left(m / s^{2}\right)$ & 1.75 & 1.32 & 0.99 & 0.99 & 0.99 & 0.99 & 1.00 & 1.00 \\
\hline & Mean $\left(\mathrm{m} / \mathrm{s}^{2}\right)$ & 1.02 & 1.00 & 0.99 & 0.99 & 0.99 & 0.99 & 0.99 & 0.99 \\
\hline & St. Dev. & 0.11 & 0.05 & 0.00 & 0.00 & 0.00 & 0.00 & 0.00 & 0.00 \\
\hline \multirow{4}{*}{ MUL279 } & $\operatorname{Min} .\left(\mathrm{m} / \mathrm{s}^{2}\right)$ & 1.66 & 1.66 & 1.66 & 1.66 & 1.66 & 1.66 & 1.66 & 1.66 \\
\hline & $\operatorname{Max} .\left(m / s^{2}\right)$ & 1.99 & 1.66 & 1.66 & 1.66 & 1.66 & 1.66 & 1.66 & 1.66 \\
\hline & $\operatorname{Mean}\left(\mathrm{m} / \mathrm{s}^{2}\right)$ & 1.67 & 1.66 & 1.66 & 1.66 & 1.66 & 1.66 & 1.66 & 1.66 \\
\hline & St. Dev. & 0.04 & 0.00 & 0.00 & 0.00 & 0.00 & 0.00 & 0.00 & 0.00 \\
\hline
\end{tabular}

${ }^{1}$ ptfa values higher than the minimum value and standard deviations greater than 0 are shown in bold. 
It is seen that the minimum values of ptfa under CLW-LN, DZC270, H-DLT362, LOS270, and MUL279 records are obtained as $1.22 \mathrm{~m} / \mathrm{s}^{2}, 1.44 \mathrm{~m} / \mathrm{s}^{2}, 0.97 \mathrm{~m} / \mathrm{s}^{2}, 0.99 \mathrm{~m} / \mathrm{s}^{2}$, and 1.66 $\mathrm{m} / \mathrm{s}^{2}$, respectively. While minimum ptfa values do not change for different population sizes, the maximum values depend on the size of the population. For example, if the population size of 5 is used under CLW-LN record, the minimum ptfa value is $1.22 \mathrm{~m} / \mathrm{s}^{2}$ while the maximum ptfa value is $2.06 \mathrm{~m} / \mathrm{s}^{2}$. In this case, the maximum error ratio is calculated as $69 \%$. Considering the population size of 10 and above, the minimum and maximum ptfa values equalize and thus, the standard deviation value is equal to 0 . In case of DZC-270 record, when $5,10,15$, and 20 populations are considered, the maximum values of ptfa are $29 \%, 8 \%$, $17 \%$, and $12 \%$ higher than those of minimum ptfa values. If the population size is taken as 25 and above, the maximum ptfa value is equal to the minimum ptfa value, and the standard deviation value is 0 . Optimization analyses performed with a population size of 5 under $\mathrm{H}$ DLT362 and MUL279 records, the error ratios are obtained as 51\% and $20 \%$ while the standard deviation values are calculated as 0.09 and 0.04 , respectively. When the population size of 10 and above is taken into consideration, the standard deviation is obtained as 0 . It has been observed that there is an error ratio of up to $77 \%$ for the population size of 5 and 10 under LOS270 record. The minimum and maximum ptfa values are equal for all population sizes between 15 and 30. For the population size of 35 and 40, the maximum values of ptfa are $1 \%$ greater than those of minimum values, but the ptfa value is equal to the minimum value, accordingly the standard deviation is 0 . Consequently, it is concluded that the population size of 25 and above would be reliable for all cases.

The convergence rate of the optimization process can also be considered as a parameter to determine the performance of population sizes. The mean convergence curves are shown in Figure 4 to examine the effects of different population sizes on convergence rates. The figure depicts the variation of ptfa with respect to the number of analyses for the case where the base displacement limit is not taken into consideration. As seen from the convergence curves, the results obtained using a population size of 5 are significantly different from the other results. When the convergence rates are examined, it can be said that there is no significant difference in the population sizes of 10 or more.

Table 3 - ptfa results obtained from 100 independent optimization process considering the base displacement limit of $15 \mathrm{~cm}$.

\begin{tabular}{lccccc}
\hline \multirow{2}{*}{$\begin{array}{l}\text { Statistical } \\
\text { results }\end{array}$} & CLW-LN & DZC270 & H-DLT362 & LOS270 & MUL279 \\
\cline { 2 - 6 } & 1.22 & 3.22 & 1.53 & 0.99 & 5.88 \\
Min. $\left(\mathrm{m} / \mathrm{s}^{2}\right)$ & 1.22 & 3.22 & 1.70 & 0.99 & 5.88 \\
Max. $\left(\mathrm{m} / \mathrm{s}^{2}\right)$ & 1.22 & 3.22 & 1.53 & 0.99 & 5.88 \\
Mean $\left(\mathrm{m} / \mathrm{s}^{2}\right)$ & 0.00 & 0.00 & 0.02 & 0.00 & 0.00 \\
St. Dev. & & & & & \\
\hline
\end{tabular}


Teaching-Learning Based Optimization of Nonlinear Isolation Systems under Far ...
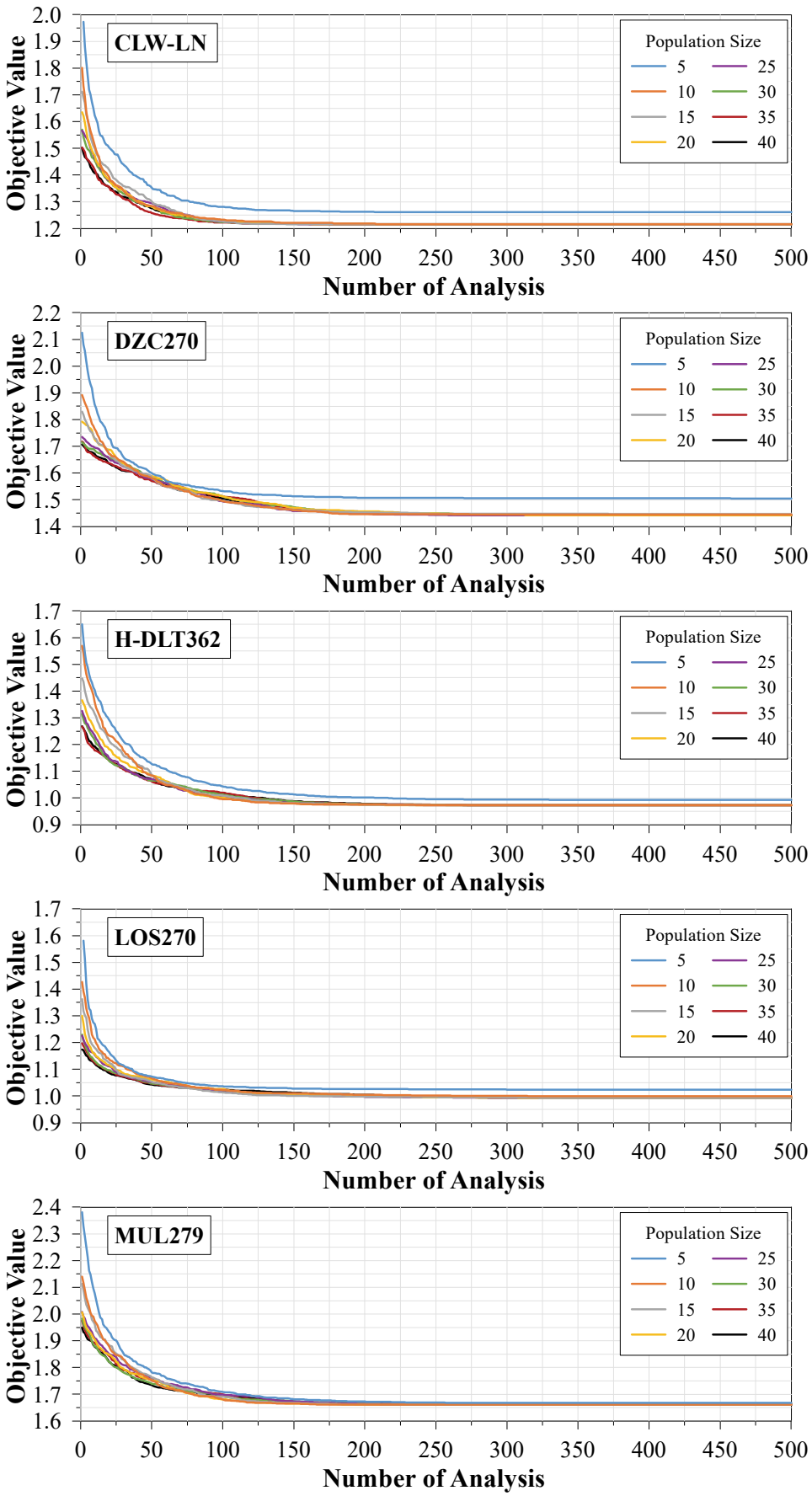

Figure 4 - Convergence curves obtained for different population sizes 
As the population size of 25 and above gives reliable results, the 100 independent optimization process with a population size of 25 is performed for each of the five different far-fault earthquake records. The variation of ptfa with respect to the number of analysis is depicted in Figure 5 for the case where the displacement limit of $15 \mathrm{~cm}$ is taken into consideration. Each figure shows 100 different optimization processes. Since the base displacements obtained from the analyses under DZC270 and MUL279 records are well above the base displacement limit of $15 \mathrm{~cm}$, penalty values are assigned to the objective function. Therefore, the objective values under DZC270 and MUL279 records are very high in the initial analysis. The statistical results in terms of ptfa obtained by the different optimization processes are presented in Table 3. Accordingly, since the standard deviation is 0 in most cases (exception: H-DLT362 where the standard deviation is 0.02 ), it is clear that the results are reliable under all earthquake records.

\subsection{Optimum Nonlinear Isolation System}

The 100 independent optimization processes with the population size of 25 aiming to minimize the peak top floor accelerations are performed under five different far-fault earthquakes with and without exceeding the base displacement constraint. The optimization process consists of iterative analyses continued until the objective function is reached. When the objective function is satisfied, the optimum nonlinear isolation system parameters including isolation period $\left(T_{0}\right)$, characteristic force ratio $\left(Q_{t} / W\right)$, and yield displacement $\left(D_{y}\right)$ are obtained. Then, the structural response in terms of peak top floor accelerations ( $p t f a)$ and peak base displacements $(p b d)$ are calculated for the corresponding optimum nonlinear isolation system. The optimum nonlinear isolation system parameters and the peak structural responses of the buildings equipped with optimum nonlinear isolation systems are reported in Table 4 and 5 under all earthquake records for cases with and without exceeding the base displacement limits, respectively. It should be noted here that the mechanical parameters of the optimum nonlinear isolation system are within the typical range for practical applications.

Table 4 - Optimum nonlinear isolation system parameters and seismic performance of the buildings equipped with optimum nonlinear isolation system not considering the base displacement limit of $15 \mathrm{~cm}$.

\begin{tabular}{lccccc}
\hline \multirow{2}{*}{$\begin{array}{c}\text { Earthquake } \\
\text { records }\end{array}$} & \multicolumn{2}{c}{ Peak structural response } & \multicolumn{3}{c}{ Optimum nonlinear isolation parameters } \\
\cline { 2 - 6 } & $p b d(\mathrm{~cm})$ & $p t f a\left(\mathrm{~m} / \mathrm{s}^{2}\right)$ & $T_{0}(\mathrm{~s})$ & $Q_{t} / W$ & $D_{y}(\mathrm{~mm})$ \\
\hline CLW-LN & 10.35 & 1.22 & 3.7 & 0.05 & 25 \\
DZC270 & $\mathbf{2 1 . 8 9}$ & 1.44 & 4.0 & 0.05 & 25 \\
H-DLT262 & $\mathbf{1 5 . 9 1}$ & 0.97 & 4.0 & 0.05 & 25 \\
LOS270 & 9.36 & 0.99 & 3.5 & 0.05 & 24 \\
MUL279 & $\mathbf{2 4 . 6 2}$ & $\mathbf{1 . 6 6}$ & $\mathbf{4 . 0}$ & $\mathbf{0 . 0 5}$ & $\mathbf{2 5}$ \\
\hline
\end{tabular}



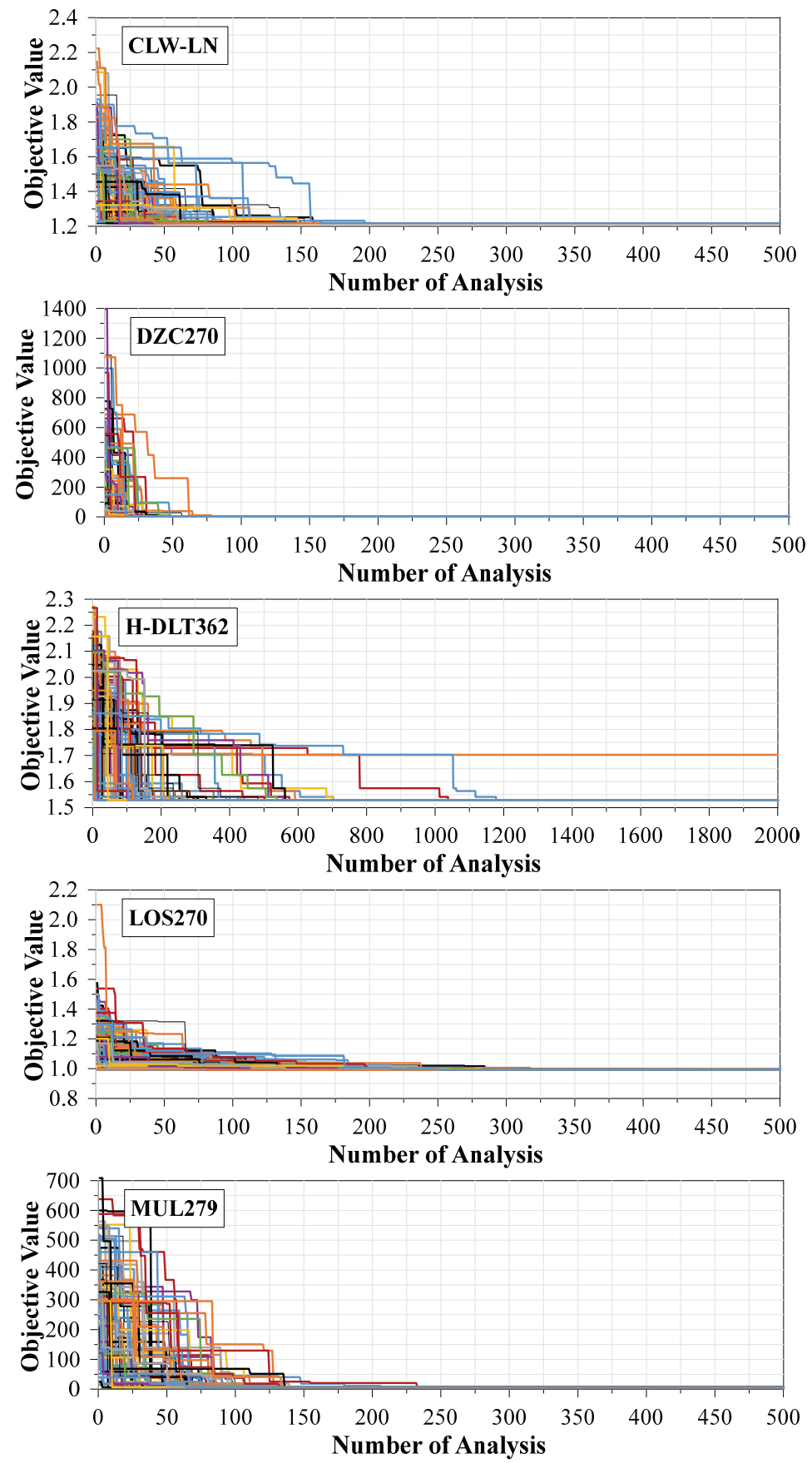

Figure 5 - The variation of ptfa with respect to analysis number under far-fault earthquake records with exceeding the base displacement limit of $15 \mathrm{~cm}$ (different lines correspond to 100 independent optimization process) 
Table 5 - Optimum nonlinear isolation system parameters and seismic performance of the buildings equipped with optimum nonlinear isolation system considering the base displacement limit of $15 \mathrm{~cm}$.

\begin{tabular}{lccccc}
\hline \multirow{2}{*}{$\begin{array}{c}\text { Earthquake } \\
\text { records }\end{array}$} & \multicolumn{2}{c}{ Peak structural response } & \multicolumn{3}{c}{ Optimum nonlinear isolation parameters } \\
\cline { 2 - 6 } & $p b d(\mathrm{~cm})$ & $p t f a\left(\mathrm{~m} / \mathrm{s}^{2}\right)$ & $T_{0}(\mathrm{~s})$ & $Q_{t} / W$ & $D_{y}(\mathrm{~mm})$ \\
\hline CLW-LN & 10.35 & 1.22 & 3.7 & 0.05 & 25 \\
DZC270 & 14.78 & $\mathbf{3 . 2 2}$ & 2.0 & 0.15 & 19 \\
H-DLT262 & 14.95 & $\mathbf{1 . 5 3}$ & 3.4 & 0.05 & 10 \\
LOS270 & 9.36 & 0.99 & 3.5 & 0.05 & 24 \\
MUL279 & $\mathbf{1 4 . 9 9}$ & $\mathbf{5 . 8 8}$ & $\mathbf{3 . 1}$ & $\mathbf{0 . 1 5}$ & $\mathbf{1 0}$ \\
\hline
\end{tabular}

As seen from Table 4, among the optimum nonlinear isolation system parameters that would perform best under all earthquakes (here the dominant earthquake record is MUL279), isolation period $\left(T_{0}\right)$, characteristic force ratio $\left(Q_{t} / W\right)$ and yield displacement $\left(D_{y}\right)$ are found as $4.0 \mathrm{~s}, 5 \%$, and $25 \mathrm{~mm}$, respectively. The $p b d$ and the ptfa are obtained under MUL279 via nonlinear time-history analyses of the building employing the optimum nonlinear isolation system, and they are calculated as $24.6 \mathrm{~cm}$ and $1.66 \mathrm{~m} / \mathrm{s}^{2}$, respectively. When the optimization analyses are conducted under different far-fault earthquakes without exceeding the base displacement limit of $15 \mathrm{~cm}$ (see Table 5), $T_{0}, Q_{t} / W$, and $D_{y}$ are determined as $3.1 \mathrm{~s}$, $15 \%$, and $10 \mathrm{~mm}$, respectively. In this case, ptfa is obtained as $5.88 \mathrm{~m} / \mathrm{s}^{2}$. Note that, considering the optimum independent variable values, dependent variable values $\left(K_{1 t}, K_{2 t}\right.$, $F_{y t}$, and $\alpha$ ) are calculated via Equations (1)-(4). Then, if desired, the isolation system elements can be dimensioned geometrically using these optimum isolation system parameters.

It can also be seen from Table 4 that $p b d$ values under DZC270, H-DLT262, and MUL279 exceed the base displacement limit of $15 \mathrm{~cm}$ where the optimum characteristic force ratio $\left(Q_{t} / W\right)$ is $5 \%$. Considering base displacement limit (Table 5), the peak base displacements obtained under all earthquake records remain below $15 \mathrm{~cm}$ while the optimum characteristic force ratio $\left(Q_{t} / W\right)$ is calculated as $15 \%$. Due to the high damping obtained by increasing the characteristic force ratio (from $5 \%$ to $15 \%$ ), ptfa values of the seismically isolated buildings under the earthquake records of DZC270, H-DLT262, MUL279 given in Table 5 are increased compared to the results obtained by not considering the base displacement limit given in Table 4.

The performance of the optimum nonlinear isolation system parameters considering the base displacement limit of $15 \mathrm{~cm}$ is also tested under other historical earthquake records and the results are given in the Table 6 . As expected, when the seismically isolated buildings with optimum parameters obtained under the most challenging earthquake record (MUL279) ae subjected to other earthquakes, they perform better than the MUL279 record.

Finally, for verifying the optimization process via TLBO, time-history analyses of non-linear isolation systems created by using parameters that deviate $\pm 10 \%$ and $\pm 20 \%$ from optimum isolation system parameters are performed under the governing earthquake record, MUL279. The results obtained from TLBO optimized cases are compared to those with non-optimum isolation system parameters and presented in Table 7 . The results show that the parameters 
of the non-linear isolation system larger or smaller than the optimum values cause either higher peak base displacement (pbd) or higher peak top floor accelerations (ptfa) than optimum analysis results.

Table 6 - Analysis result of nonlinear isolation systems with optimum parameters under MUL279 $\left(T_{0}=3.1 \mathrm{~s}, Q_{t} / W=0.15, D_{y}=10 \mathrm{~mm}\right)$

\begin{tabular}{lcc}
\hline \multirow{2}{*}{$\begin{array}{c}\text { Earthquake } \\
\text { records }\end{array}$} & \multicolumn{2}{c}{ Peak structural response } \\
\cline { 2 - 3 } & $p b d(\mathrm{~cm})$ & $p t f a\left(\mathrm{~m} / \mathrm{s}^{2}\right)$ \\
\hline CLW-LN & 10 & 5.46 \\
DZC270 & 14.4 & 4.75 \\
H-DLT262 & 7.4 & 4.78 \\
LOS270 & 12.2 & 4.86 \\
MUL279 & 14.99 & 5.88 \\
\hline
\end{tabular}

Table 7 - Analysis result of nonlinear isolation system parameters deviating from optimum under MUL279.

\begin{tabular}{cccccc}
\hline $\begin{array}{c}\text { Deviation of isolation } \\
\text { system parameters from } \\
\text { optimum }\end{array}$ & \multicolumn{2}{c}{$\begin{array}{c}\text { Non-linear isolation } \\
\text { system parameters }\end{array}$} & \multicolumn{2}{c}{$\begin{array}{c}\text { Peak structural } \\
\text { response }\end{array}$} \\
\cline { 2 - 6 } & $T_{0}(\mathrm{~s})$ & $Q_{t} / W$ & $D_{y}(\mathrm{~mm})$ & $p b d(\mathrm{~cm})$ & $p t f a\left(\mathrm{~m} / \mathrm{s}^{2}\right)$ \\
\hline optimum & 3.1 & 0.15 & 10 & 14.99 & 5.88 \\
$-10 \%$ & 2.79 & 0.14 & 9 & 15.46 & 5.63 \\
$+10 \%$ & 3.41 & 0.17 & 11 & 14.55 & 6.20 \\
$-20 \%$ & 2.48 & 0.12 & 8 & 16.55 & 5.45 \\
$+20 \%$ & 3.72 & 0.18 & 12 & 14.28 & 6.54 \\
\hline
\end{tabular}

\section{CONCLUSIONS}

In this study, optimization of nonlinear isolation system parameters via Teaching-Learning Based Optimization (TLBO) algorithm is presented in the context of a medium-rise prototype building exposed to historical far-fault earthquakes. The objective function in determining the optimum values of the isolation system parameters is set as minimizing peak top floor acceleration with and without exceeding a specified base displacement. Main accomplishments and findings can be listed as follows:

- A methodology is developed where the optimization process is carried out by recursively running 3D-BASIS software, which performs non-linear time-history 
analyses, with an in-house optimization program, which is constructed in MATLAB, that employs TLBO algorithm.

- Population size affects algorithm performance and the appropriate population size for the problem at hand should be determined individually. For the problem evaluated in this study, a population size of 25 was found to be the minimum size required for obtaining a reliable solution.

- As an alternative, the convergence rate of the optimization process can also be considered as a parameter to determine the performance of population sizes.

- The standard deviation of the objective function is obtained as almost 0 for even very small population sizes (i.e 10), indicating that the metaheuristic optimization algorithm TLBO is robust in determining optimum nonlinear isolation system parameters.

- It is shown that using an appropriate population size, TLBO is a robust optimization method that yields optimum values of the non-linear isolation system parameters for achieving minimum peak floor accelerations without exceeding a specified peak base displacement limit under a set of far-fault earthquakes.

- For the benchmark building evaluated here, specifying a base displacement limit resulted in increased characteristic force ratios which indirectly caused increases in peak floor accelerations compared to the case where no limit was specified for the base displacement.

\section{References}

[1] Naeim, F., Kelly, J., Design of Seismic Isolated Structures: from Theory to Practice, Newyork. Wiley, 1999.

[2] Martelli, A., Seismic Isolation and Energy Dissipation: Worldwide Application and Perspectives, Earthquake Resistant Engineering Structures VI, Boston, WIT Press, 2007.

[3] Cheng, F.Y., Jiang, H., Lou, K., Smart Structures: Innovative Systems for Seismic Response Control, New York, CRC press, 2008.

[4] Nagarajaiah, S., Xiahong, S., Response of Base-isolated USC Hospital Building in Northridge Earthquake, J. Struct. Eng., 126-10, 1177-1186, 2000.

[5] Goldberg, D.E., Genetic Algorithms in Search, Optimization, and Machine Learning, Machine Learning, 3:2, 95-99,1988.

[6] Dorigo, M., Maniezzo, V., Colorni, A., Ant system: Optimization by a Colony of Cooperation Agents, IEEE Transactions on Systems, Man, and Cybernetics, Part B: Cybernetics, 26:1, 29-41, 1996.

[7] Kennedy, J., Eberhart, R., Particle Swarm Optimization, IEEE International Conference on Neural Networks, Perth, WA, Australia, 1995. 
[8] Karaboga, D., Basturk, B.. A Powerful and Efficient Algorithm for Numerical Function Optimization: Artificial Bee Colony (ABC) Algorithm, Journal of Global Optimization, 39(3), 459-471, 2007.

[9] Rao, R.V., Savsani, V.J., Vakharia, D.P., Teaching-learning-based Optimization: A novel Method for Constrained Mechanical Design Optimization Problems, ComputerAided Design, 43:3, 303-315, 2011.

[10] Matsagar, V.A., Jangid, R.S., Influence of Isolator Characteristic on the Response of Base-isolated Structures, Engineering Structures, 26, 1735-1749, 2004.

[11] Dicleli, M., Buddaram, S., Effect of Isolator and Ground Motion Characteristics on the Performance of Seismic- Isolated Bridges, Earthquake Engineering \& Structural Dynamics 35, 233-250, 2006.

[12] Alhan, C., Öncü-Davas, S., Performance Limits of Seismically Isolated Buildings under Near-field Earthquakes, Engineering Structures, 116, 83-94, 2016.

[13] Nigdeli, S.M., Bekdaş, G., Alhan, C., Optimization of Seismic Isolation Systems via Harmony Search, Engineering Optimization, 46:11, 1553-1569, 2014.

[14] Çerçevik, A.E., Avşar, Ö., Doğrusal Sismik İzolasyon Parametrelerinin Karga Arama Algoritması ile Optimizasyonu. Pamukkale Üniversitesi Mühendislik Bilimleri Dergisi, DOI: 10.5505/pajes.2019.93636.

[15] Pourzeynali, S., Zarif, M. Multi-objective Optimization of Seismically Isolated Highrise Building Structures using Genetic Algorithms, Journal of Sound and Vibration, 311(3-5), 1141-1160, 2008.

[16] Rao, R.V., Waghmare, G., Design Optimization of Robot Grippers using TeachingLearning-Based Optimization Algorithm, Advanced Robotics, 29(6), 431-447, 2015.

[17] Camp, C.V., Farshchin, M., Design of Space Trusses Using Modified TeachingLearning-Based Optimization, Engineering Structures, 62, 87-97, 2014.

[18] Degertekin, S. O., Hayalioglu, M.S., Sizing Truss Structures using Teaching-LearningBased Optimization, Computers \& Structures, 119, 177-188, 2013.

[19] Temur, R., Bekdaş, G., Teaching Learning-Based Optimization for Design of Cantilever Retaining Walls, Structural Engineering and Mechanics, 57(4), 763-783, 2016.

[20] Nagarajaiah, S., Reinhorn, A.M., Constantinou, M.C., Nonlinear Dynamic Analysis of 3D Base-isolated Structures, J Struct Eng, 117:2035-54, 1991.

[21] Nagarajaiah, S., Reinhorn, A.M., Constantinou, M.C., 3D-Basis: Nonlinear Dynamic Analysis of Three-dimensional Base Isolated Structures: Part II. Technical Report NCEER-91-0005. National Center for Earthquake Engineering, State University of New York at Buffalo; 1991.

[22] Pan, P., Zamfirescu, D., Nakashima, M., Nakayasu, N., Kashiwa, H., Base-isolation Design Practice in Japan: Introduction to the Post-Kobe Approach, J Earthq Eng, 9:1, 147-171, 2005. 
[23] Makris, N., Chang, S., Effect of Viscous, Viscoplastic and Friction Damping on the Response of Seismic Isolated Structures, Earthq Eng Struct Dyn, 29, 85-107, 2000.

[24] Dicleli, M., Buddaram, S., Equivalent Linear Analysis of Seismic-isolated Bridges Subjected to Near-field Ground Motions with Forward Rupture Directivity Effect, Engineering Structures, 29, 21-32, 2007.

[25] Providakis, C.P., Effect of Supplemental Damping on LRB and FPS Seismic Isolators under Near-field Excitations, Soil Dyn Earthq Eng, 29, 80-90, 2009.

[26] Tavakoli, H.R., Naghavi, F., Goltabar, A.R., Dynamic Responses of the Base-fixed and Isolated Building Frames under Far-and Near-fault Earthquakes, Arabian Journal for Science and Engineering, 39(4), 2573-2585, 2014.

[27] Bhandari, M., Bharti, S.D., Shrimali, M.K., Datta, T.K., The Numerical Study of Baseisolated Buildings under Near-field and Far-field Earthquakes, Journal of Earthquake Engineering, 22(6), 989-1007, 2018.

[28] Fathi, M., Makhdoumi, A., Parvizi, M., Effect of Supplemental Damping on Seismic Response of Base Isolated Frames under Near \& Far Field Accelerations, KSCE Journal of Civil Engineering, 19(5), 1359-1365, 2015.

[29] FEMA Quantification of Building Seismic Performance Factors, Report FEMA P695 Federal Emergency Management Agency, 2009.

[30] PEER, Pacific Earthquake Engineering Resource Center: NGA Database https://ngawest2.berkeley.edu/, [access: February 2019]. 
